\title{
PELATIHAN PEMBUATAN MEDIA PEMBELAJARAN ATTRACTIVE DAN LONG LASTING GUNA MENINGKATKAN KOMPETENSI PEDAGOGIK GURU MGMP BAHASA INGGRIS MADRASAH TSANAWIAH SE-KABUPATEN MADIUN
}

\author{
Rosita Ambarwati ${ }^{1)}$, Dwi Rosita Sari ${ }^{2}$ \\ ${ }^{1)}$ FPBS KIP PGRI MADIUN \\ email: paramitthagita@yahoo.com \\ ${ }^{2)}$ FPBS IKIP PGRI MADIUN \\ email: rositasaridwi@yahoo.com
}

\begin{abstract}
Workshops and seminars in the field of education has been widely implemented, but it is still rarely discussed in detail about creating instructional media. In addition, observations of teachers' competence of MGMP Madrasah Tsanawiah Kabupaten Madiun, it can be said that the competence of most teachers are still weak. Most teachers still have many obstacles in achieving the learning objectives. This condition as a background of this teachers' training on making attractive and long lasting media. The success of this program will be seen from (1) the existence of a positive change in attitude and a new understanding of teachers that English learning process can be more fun with the learning media ; (2) the emergence of understanding of the various media that attractive and long lasting in English subject; and (3) the emergence of innovations in the application of learning media in the classroom
\end{abstract}

Key words : Teachers' Pedagogy Competence, Attractive and Long Lasting Media

\section{PENDAHULUAN}

Proses pembelajaran memerlukan input pendidik yang berkompeten agar proses pembelajaran dapat mencapai hasil yang maksimal. Pendidik yang berkompeten adalah para pendidik yang memiliki kompetensi yang baik, salah satunya adalah Kompetensi Pedagogik. Kompetensi pedagogik ini mencakup persiapan seorang pendidik dalam pelaksanaan aktifitas pembelajaran serta segala penunjang aktifitas tersebut termasuk didalamnya penggunaan media yang mampu menarik minat dan perhatian siswa untuk belajar.

Pembelajaran merupakan suatu proses kegiatan yang di dalamya tergabung suatu sistem kompleks yang tercermin dalam tujuan pembelajaran, kompetensi yang harus dicapai siswa, metode pembelajaran, media pembelajaran, sumber belajar, evaluasi dan komponen-komponen lain. Sistem tersebut harus dijalankan secara menyatu berdasarkan karakteristik masing-masing komponen untuk mencapai kompetensi yang diharapkan.

Berdasarkan rasionalitas tersebut diharapkan akan terbentuk guru yang profesional sebagaimana tercantum dalam UU Guru dan Dosen Nomor 14 Tahun 2005. UU tersebut menyatakan bahwa guru (bahasa Inggris) hendaklah memiliki kompetensi di bidangnya. Kompetensi adalah seperangkat pengetahuan, ketrampilan dan perilaku yang harus dimiliki, dihayati serta dikuasai oleh calon guru bahasa Inggris dalam melaksanakan tugas profesionalnya. Kompetensi tersebut meliputi kompetensi akademik, pedagogik, sosial, kepribadian serta profesional.

Kompetensi akademik yang harus dimiliki calon guru bahasa Inggris adalah menguasai materi sedangkan kompetensi pedagogik meliputi: (1) memahami siswa, (2) mampu merancang dan melaksanakan pembelajaran, meliputi pemilihan media dan metode yang relevan dengan materi ajar, (3) mampu mengevaluasi hasil pembelajaran dengan baik, dan (4) mampu menggerakkan siswa umtuk mengaktualisasikan diri. Mengamati dan mempelajari proses pembelajaran yang ada khususnya pada program studi Pendidikan Bahasa Inggris dapat dikatakan bahwa proses pembelajaran masih mengalami kendala atau dengan kata lain belum dapat mencapai hasil yang memuaskan. Hal tersebut bisa dilihat dari kurangnya intensitas para guru yang menggunakan media pembelajaran dalam 
proses mengajar yang selama ini masih didominasi dari penggunaan media pembelajan berupa textbook saja. Kekurangmaksimalan pemahaman dalam pemilihan media tersebut berakibat pada proses pembelajaran yang kurang atraktif dan efisien.

Sejalan dengan hal tersebut berdasarkan hasil observasi peneliti dan wawancara dengan para guru Bahasa Inggris tingkat Tsanawiyah seKabupaten Madiun, pelatihan pembuatan dan pengaplikasian pembuatan media pembelajaran yang sesuai dengan materi belum terlalu banyak dilaksanakan. Workshop maupun seminar belum banyak menyentuh tentang media pembelajaran. Dari seluruh rangkaian permasalahn tersebut para guru masih butuh bimbingan secara intensif untuk bisa mencapai tujuan pembelajaran dengan baik.

\section{METODE PELAKSANAAN PROGRAM}

Kegiatan Pengabdian Kepada Masyarakat ini dilakukan di area kabupaten madiun yang mencakup 15 kecamatan. Dalam pelaksanaannya, kegiatan ini akan difokuskan di daerah Balerejo, dikarenakan tempat pelaksanaan MGMP Madrasah Tsanawiah (MTs) se-kabupaten Madiun berada di kecamatan ini. Kegiatan pengabdian ini dilakukan selama 10 bulan, mulai bulan Januari 2014 sampai dengan November 2014.

Desain kegiatan Pengabdian Kepada Masyarakat ini dibagi menjadi 5 (empat) kegiatan utama yaitu (1) Analisis Situasi, (2) Persiapan, (3) Pelatihan, (4) Pembimbingan, dan (5) Penentuan Ketercapaian Indikator Keberhasilan/ Target Kegiatan.

\section{HASIL DAN PEMBAHASAN \\ a. Analisis Situasi}

Berdasarkan hasil observasi peneliti dan wawancara dengan para guru Bahasa Inggris tingkat Tsanawiyah se- Kabupaten Madiun, pelatihan pembuatan dan pengaplikasian pembuatan media pembelajaran yang sesuai dengan materi belum terlalu banyak dilaksanakan. Workshop maupun seminar belum banyak menyentuh tentang media pembelajaran. Dari seluruh rangkaian permasalahn tersebut para guru masih butuh bimbingan secara intensif untuk bisa mencapai tujuan pembelajaran dengan baik.

\section{b. Persiapan}

Sehubungan dengan analisis situasi permasalahan mitra sebagaimana dipaparkan, maka peneliti melakukan langkah dengan membuat program pelatihan yang akan dilengkapi pendampingan kepada guru anggota MGMP Bahasa Inggris Madrasah Tsanawiyah (MTs) Se-Kabupaten Madiun. Dalam fase persiapan ini peneliti membuat kesepakatan melalui kontrak kerjasama dan menyusun rancangan kegiatan. Untuk legalitas kegiatan tersebut maka peneliti melakukan koordinasi dengan dinas pendidikan kabupaten Madiun.

\section{c. Pelatihan}

Pada tahap pelatihan, tim melakukan pelatihan berupa pemamaparan media pembelajaran, pemaparan proses pembuatan media, diskusi cara penerapan metode dalam pembelajaran, dan praktik pembuatan media serta pengaplikasianya didalam kelas. Pelaksanaan program pelatihan ini diikuti 20 guru, dimulai pukul 09.00 sampai dengan pukul 11.30 tepatnya hari Sabtu, 23 Agustus 2014 Pemberian materi ini diberikan oleh ibu Dwi Rosita Sari, S.Pd, M.Pd.

\section{d. Pembimbingan}

Pada tahap ini dilakukan pembimbingan dalam menentukan media pembelajaran yang sesuai dengan tema pembelajaran. Secara detail dapat kami sampaikan bahwa proses pembimbingan dimulai setelah guru memilih satu tema dalam pembelajaran Bahasa Inggris kemudian memutuskan media apa yang paling sesuai dengan materi yang akan diajarkan. Proses pembimbingan ini dilakukan oleh tim peneliti/pelaksana (dosen) sampai berhasil menghasilkan produk media pembelajaran. Selanjutnya, guru mempresentasikan dan mempraktikkan hasil bimbingan di kegiatan MGMP sebagai kegiatan sharing dan penambahan pengetahuan satu dengan yang lain; dan guru memperoleh feedback dari teman sejawat dan dosen perihal presentasi dan implementasi.

\section{e. Penentuan Ketercapaian Indikator Target Kegiatan}

Proses pelatihan dan pembimbingan pada kegiatan ini masih harus dilakukan perbaikanperbaikan. Kendala yang muncul adalah pada pelatihan yang berhubungan dengan media elektronik 


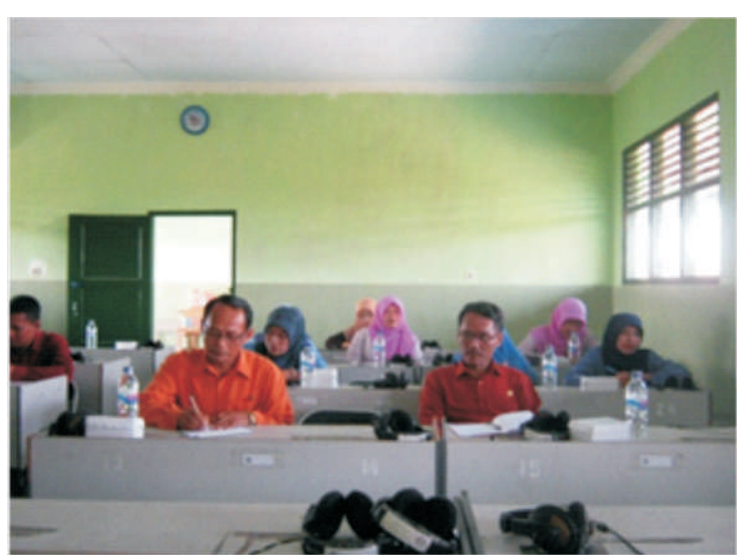

Gambar 1. Kegiatan Pelatihan

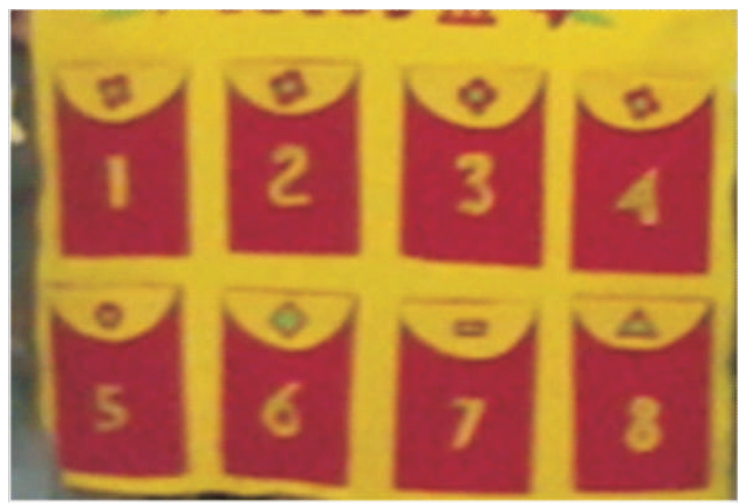

Gambar 2. Contoh Media Attractive dan Long Lasting

\section{KESIMPULAN}

Berdasarkan uraian diatas pelatihan pembuatan media ini sangat dibutuhkan oleh guru-guru yang tergabung dalam MGMP Madrasah Tsanawiah (MTs) se-kabupaten Madiun. Pelatihan ini mampu meningkatkan kemampuan pedagogik para guru dalam proses pembelajaran terutama proses penyampaian materi yang dianggap lebih mudah dan efektif karena adanya media pembelajaran yang menarik dan bisa dipakai berulang-ulang.

\section{REFERENSI}

Bafadal, I. (2003). Peningkatan Profesional Guru SD. Jakarta: Bumi Aksara.

Depdiknas. (2005). Undang Undang Republik Indonesia tentang Guru dan Dosen Nomer 14 tahun 2005. Jakarta: Depdiknas RI

Sanjaya, W. (2006). Strategi Pembelajaran. Jakarta: Media Abadi.

Saud, U. S. (2009). Pengembangan Profesi Guru. Bandung: CV. Alfabeta.

Soetjipto, dan Kosasi, R. (2004). Profesi Keguruan. Jakarta: Rineka Cipta. 